\title{
Metagenomic analysis of microbial consortium from natural crude oil that seeps into the marine ecosystem offshore Southern California
}

\author{
Erik R. Hawley ${ }^{1}$, Hailan Piao ${ }^{1}$, Nicole M. Scott ${ }^{2}$, Stephanie Malfatti ${ }^{3}$, Ioanna Pagani ${ }^{4}$, Marcel \\ Huntemann ${ }^{4}$, Amy Chen ${ }^{4}$, Tijana Glavina del Rio ${ }^{4}$, Brian Foster ${ }^{4}$, Alex Copeland ${ }^{4}$, Janet \\ Jansson $^{4,5}$, Amrita Pati ${ }^{4}$, Susannah Tringe ${ }^{4,5}$, Jack A. Gilbert ${ }^{2,6}$, Thomas D. Lorenson ${ }^{7}$, \\ Matthias Hess ${ }^{1,4,8,9,10^{*}}$ \\ ${ }^{1}$ Washing ton State University Tri-Cities, Richland, WA, USA \\ ${ }^{2}$ Argonne National Laboratory, Lemont, IL, USA \\ ${ }^{3}$ Lawrence Livermore National Laboratory, Biosciences and Biotechnology Division, \\ Livermore, CA, USA \\ ${ }^{4}$ DOE Joint Genome Institute, Walnut Creek, CA, USA \\ ${ }^{5}$ Lawrence Berkeley National Laboratory, Berkeley, CA, USA \\ ${ }^{6}$ University of Chicago, Chicago, IL, USA \\ ${ }^{7}$ USGS, Menlo Park, CA, USA \\ ${ }^{8}$ Washing ton State University, Pullman, WA, USA \\ ${ }^{9}$ Pacific Northwest National Laboratory, Chemical \& Biological Process Development \\ Group, Richland, WA, USA \\ ${ }^{10}$ Environmental Molecular Sciences Laboratory, Richland, WA, USA \\ *Correspondence: Matthias Hess (mhess@lbl.gov)
}

Keywords: Bioremediation, hydrocarbon-degradation, marine ecosystem, crude oil, natural oil seeps, anaerobic methane oxidation, bacteria, archaea, metagenomics

Crude oils can be major contaminants of the marine ecosystem and microorganisms play a sig nificant role in the degradation of its main constituents. To increase our understanding of the microbial hydrocarbon deg radation process in the marine ecosystem, we collected crude oil from an active seep area located in the Santa Barbara Channel (SBC) and generated a total of about 52 Gb of raw metagenomic sequence data. The assembled data comprised $\sim 500 \mathrm{Mb}$, representing $\sim 1.1$ million genes derived primarily from chemolithoautotrophic bacteria. Members of Oceanospirillales, a bacterial order belonging to the Deltaproteobacteria, recruited less than $2 \%$ of the assembled genes within the SBC metagenome. In contrast, the microbial community associated with the oil plume that developed in the aftemath of the Deepwater Horizon (DWH) blowout in 2010, was dominated by Oceanospirillales, which comprised more than $60 \%$ of the metagenomic data generated from the DWH oil plume. This suggests that Oceanospirillales might play a less significant role in the microbially mediated hydrocarbon conversion within the SBC seep oil compared to the DWH plume oil. We hypothesize that this difference results from the SBC oil seep being mostly anaerobic, while the DWH oil plume is aerobic. Within the Archaea, the phylum Euryarchaeota, recruited more than $95 \%$ of the assembled archaeal sequences from the SBC oil seep metagenome, with more than 50\% of the sequences assigned to members of the orders Methanomicrobiales and Methanosarcinales. These orders contain organisms capable of anaerobic methanogenesis and methane oxidation (AOM) and we hypothesize that these orders - and their metabolic capabilities - may be fundamental to the ecology of the SBC oil seep.

Abbreviations: ANME- anaerobic methanotrophic archaea, AOM- anaerobic methane oxidation, DWH- Deepwater Horizon, eDNA- environmental DNA, GoM- Gulf of Mexico, SBCSanta Barbara Channel, SRB- Sulfur reducing bacteria 


\section{Introduction}

Oil-exposed marine microbial consortia are known to be capable of degrading hydrocarbons [1]. Hydrocarbon-degrading microbes have been used successfully in the remediation of oil that contaminated long stretches of shorelines [2,3]; and it was endorsed anew as a promising remediation strategy after the Deepwater Horizon (DWH) blowout [4]. Despite the significant resources that have been spent to study the microbial response to oil spills, most of the research data come from culture-based studies and relatively little is known about the dynamics and microbial processes that occur during the biological degradation of crude oil in uncontrolled and highly complex biological systems [5-8]. Advances in DNA sequencing technologies and computation provide insights into the metabolic blueprint of microbial cells and microbial communities directly from environmental samples. This has facilitated a better understanding of the genes and metabolic processes that underlie the phenotypes of individual cells and complex communities - without depending on axenic microbial cultures $[9,10]$. The potential of DNA sequencing to improve our understanding of microbial responses to large oil spills, was recognized immediately by the scientific community following the 4 million barrel DWH spill released into the Gulf of Mexico (GoM), resulting in a number of studies that employed metagenomics and metatranscriptomics to map the communities genetic response so as to eventually develop more sustainable remediation strategies [4,11-14]. The GoM has many natural oil seeps, which have primed the microbial community to be ready for larger spills. As the composition of the natural microbial community at a spill site could have a significant role in the bioremediation process following an oil spill [15] and considering that oil spills are not restricted to the GoM, it will be crucial to build an extended knowledgebase of native hydrocarbon degrading microbiomes from different geographical locations. Here we report on the first metagenome exceeding $50 \mathrm{~Gb}$ of raw DNA sequence data from a microbial community associated with natural crude oil seeps of the Santa Barbara Channel (SBC), one of the world's largest natural hydrocarbon seep regions [16], which can be accessed publicly through $\underline{\mathrm{IMG} / \mathrm{M}}$ for further analysis by the scientific community.

\section{Classification and features}

A metagenome was generated from a hydrocarbonadapted consortium collected using a remotely operated vehicle from a submarine oil seep located near Coal Oil Point at $34.39192^{\circ} \mathrm{N}, 119.84578^{\circ} \mathrm{W}$, $79.4 \mathrm{~m}$ below sea level [Table 1]. The collected oil samples were transported immediately to the laboratory and stored at $-20^{\circ} \mathrm{C}$ until DNA extraction was performed. Further details of sampling location and oil geochemistry have been described previously by Lorenson and colleagues [19].

\section{Metagenome sequencing information Metagenome project history}

This is the first metagenome associated with natural crude oils that seep into the SBC. The site was selected based on its geographical location near active offshore drilling and the distinct geochemical composition of SBC seep oils compared to those from the GoM. Sequence analysis of small subunit ribosomal RNA gene amplicons identified 1,045 taxa based on $97 \%$ sequence identity, and a fingerprint that is distinct from the community associated with the oil plume that formed after the DWH accident [20].

\section{Growth conditions and DNA isolation}

Environmental DNA (eDNA) was extracted from the seep oil sample using a FastDNA Spin Kit for Soil from MP Biomedicals according to the manufacturer's protocol with $500 \mathrm{mg}$ of the seep oil as starting material. Bead-beating was conducted three times for 20 seconds using a MiniBeadbeater-16 (Biospec Products, Bartlesville, OK, USA). Samples were kept on ice for 1 min between each round of bead-beating. Extracted eDNA was resuspended in a total of $100 \mu \mathrm{L}$ DNase/PyrogenFree $\mathrm{H}_{2} \mathrm{O}$. Concentration of obtained eDNA was measured using a Qubit 2.0 Fluorometer (Life Technologies, Grand Island, NY) according to the manufacturer's protocol. The quantity and quality of the extraction were checked by gel electrophoresis using standards for standard operational procedures of the Joint Genome Institute (JGI).

\section{Metagenome sequencing and assembly}

A total of $51.7 \mathrm{Gbp}$ were generated from the oilassociated microbiome. Starting material (200ng of DNA) was sheared to $270 \mathrm{bp}$ using the Covaris E210 (Covaris) and size selected using SPRI beads (Beckman Coulter). The fragments were treated with end-repair, A-tailing, and ligation of Illumina compatible adapters (IDT, Inc) using the KAPA- 
Illumina library creation kit (KAPA Biosystems). The prepared sample libraries were quantified by qPCR using KAPA Biosystem's next-generation sequencing library qPCR kit and run on a Roche LightCycler 480 real-time PCR instrument. The quantified sample libraries were then prepared for sequencing on the Illumina HiSeq2000 sequencing platform, utilizing a TruSeq paired-end cluster kit, v3, and Illumina's cBot instrument to generate clustered flowcells for sequencing. Sequencing of the flowcells was performed on the Illumina HiSeq2000 platform using a TruSeq SBS sequencing kit 200 cycles, v3, following a 2x150 indexed run recipe. Raw metagenomic reads were trimmed using a minimum quality score cutoff of 10. Trimmed, paired-end Illumina reads were assembled using SOAPdenovo v1.05 [21] with a range of Kmers $(81,85,89,93,97,101)$. Default settings for all SOAPdenovo assemblies were used (flags: $-\mathrm{d} 1$ and $-\mathrm{R}$ ). Contigs generated by each assembly (6 total contig sets) were sorted into two pools based on length. Contigs smaller than 1,800 bp were assembled using Newbler (Life Technologies, Carlsbad, CA) in an attempt to generate larger contigs (flags: -tr, -rip, -mi 98, -ml 80). All assembled contigs larger than $1,800 \mathrm{bp}$, as well as the contigs generated from the final Newbler run, were combined using minimus 2 (flags: -D MINID=98 -D OVERLAP=80) [AMOS [22]] Read depth estimations were based on mapping of the trimmed, screened, paired-end Illumina reads to assembled contigs with BWA [23]. The unassembled, paired reads were merged with FLASH [24]. The assembled contigs along with the merged, un-assembled reads were submitted to IMG/M for functional annotation. Sequences are publicly available at IMG/M under the project ID 45292. Table 2 summarizes the project information and its association with MIGS version 2.0 compliance [17].

Table 1. Classification and general features of the metag enome data set according to the Minimum Information about Genomes and Metagenomes (MIMS) standards [17].

\begin{tabular}{|c|c|c|c|}
\hline MIMS ID & Property & Term & Evidence code $^{a}$ \\
\hline \multirow[t]{7}{*}{ MIM 3} & Study Name & $\begin{array}{l}\text { Marine microbial communities from } \\
\text { the Santa Barbara Channel oil seeps }\end{array}$ & \\
\hline & Sample Name & Crude oil metag enome 2 & \\
\hline & GOLD classification: Ecosystem & Environmental & NAS \\
\hline & GOLD classification: Ecosystem Categ ory & Aquatic & \\
\hline & GOLD classification: Ecosystem Type & Marine & \\
\hline & GOLD classification: Ecosystem Subtype & Oil seeps & \\
\hline & GOLD classification: Specific Ecosystem & unclassified & \\
\hline \multirow[t]{2}{*}{ MIGS-2 2} & Carbon source & Seep oil & NAS \\
\hline & Energy source & Seep oil & NAS \\
\hline MIGS-6 & Habitat & Aquatic, Marine, Oil seeps & NAS \\
\hline MIGS-14 & Pathog enicity & none & NAS \\
\hline MIGS-4 & Geographic location & Marine ecosystem, California, USA & NAS \\
\hline MIGS-5 & Sample collection time & June, 2009 & NAS \\
\hline MIGS-4.1 & Latitude & 34.39192 & NAS \\
\hline MIGS-4.2 & Long itude & -119.84578 & NAS \\
\hline MIGS-4. 3 & Depth & $79.4 \mathrm{~m}$ & NAS \\
\hline
\end{tabular}

${ }^{a}$ Evidence codes - NAS: Non-traceable Author Statement (i.e. not directly observed for the living, isolated sample, but based on a generally accepted property for the species, or anecdotal evidence). These evidence codes are from the Gene Ontology project [18]. 
Table 2. Project information

\begin{tabular}{lll}
\hline MIGS ID & Property & Term \\
\hline MIGS-31 & Finishing quality & Standard Draft \\
MIGS-28 & Libraries used & Illumina standard paired-end library (0.27 kb insert size) \\
MIGS-29 & Sequencing platforms & Illumina HiSeq2000 \\
MIGS-31.2 & Fold coverage & NA \\
MIGS-30 & Assemblers & SOAPdenovo v1.05, Newbler v2.5, minimus2 \\
MIGS-32 & Gene calling method & Genemark > Prodigal > Metag ene > Frag GeneScan \\
& GOLD ID & Gm0045292 \\
& GOLD sample ID & Gs0002474 \\
& IMG Project ID & 45292 \\
& Project relevance & biodeg radation of pollutants, biotechnological
\end{tabular}

\section{Metagenome annotation}

Prior to annotation, all sequences were trimmed to remove low quality regions falling below a minimum quality of Q13, and stretches of undetermined sequences at the ends of contigs were removed. Each sequence was checked with the DUST algorithm [25] from the NCBI toolkit for low complexity regions and sequences with less than 80 unmasked nt were removed. Additionally very similar sequences (similarity > 95\%) with identical 5' pentanucleotides are replaced by one representative, typically the longest, using uclust [26]. The feature prediction pipeline included the detection of non-coding RNA genes (tRNA, and rRNA), followed by prediction of protein coding genes. Identification of tRNAs was performed using tRNAScan-SE-1.23 [27]. In case of conflicting predictions, the best scoring predictions were selected. Since the program cannot detect fragmented tRNAs at the end of the sequences, we also checked the last $150 \mathrm{nt}$ of the sequences by comparing these to a database of nt sequences of tRNAs identified in the isolate genomes using blastn [28]. Hits with high similarity were kept; all other parameters are set to default values. Ribosomal RNA genes (tsu, ssu, lsu) were predicted using the hmmsearch [29] with internally developed models for the three types of RNAs for the domains of life.

Identification of protein-coding genes was performed using four different gene calling tools, GeneMark (v.2.6r) [30], Metagene (v. Aug08) [31], Prodigal (v2.50) [32] and FragGeneScan [33] all of which are $a b$ initio gene prediction programs. We typically followed a majority rule based decision scheme to select the gene calls.
When there was a tie, we sel ected genes based on an order of gene callers determined by runs on simulated metagenomic datasets (Genemark > Prodigal $>$ Metagene $>$ FragGeneScan). At the last step, CDS and other feature predictions were consolidated. The regions identified previously as RNA genes were preferred over proteincoding genes. Functional prediction followed and involved comparison of predicted protein sequences to the public IMG database (db) using the usearch algorithm [26], the COG db using the NCBI developed PSSMs [34], and the pfam db [35] using hmmsearch. Assignment to KEGG Ortholog protein families was performed using the algorithm described in [36].

\section{Metag enome properties}

The metagenome presented here contains $333,405,037$ high-quality reads, totaling $50,010,755,550 \mathrm{bp} .38 .80 \%$ of the reads were assembled into a total of 803,203 scaffolds, representing 495,862,225 bp, with 91,522 scaffolds $\geq 1$ $\mathrm{kb}, 1,354$ scaffolds $\geq 10 \mathrm{~kb}, 103$ scaffolds $\geq 25 \mathrm{~kb}, 6$ scaffolds $\geq 50 \mathrm{~kb}$ and 1 scaffold $\geq 250 \mathrm{~kb}$. The GC content of the assembled metagenome was $44.95 \%$, which is slightly higher compared to the $40.95 \%$ observed for the assembled metagenome from the oil plume (IMG ID 1892) that formed in the GoM after the DWH blowout in 2010 [14].

The assembled sequences included 1,143,552 predicted genes with $99.32 \%$ annotated as protein-coding genes. A total of 770,455 of the protein coding genes, corresponding to $67.37 \%$ of the total predicted protein-coding genes, were as- 
signed to a putative family or function based on the presence of conserved Pfam domains with the remaining genes annotated as hypothetical proteins. The properties and the statistics of the metagenome are summarized in Table 3.

From the 1,135,810 genes predicted to encode proteins, $620,853(54.66 \%)$ were assigned to one of the 25 general COG categories [Table 4]. Within genes for which a function could be as signed, most genes were assigned to COG categories (E) and (C), which are associated with amino acid transport and energy production and conversion respectively.

\section{Taxonomic gene diversity}

The taxonomic diversity and phylogenetic structure of the oil metagenome were determined based on the assembled genes, classifying at a minimum $60 \%$ identity to members of the listed phyla. The phylogeny reported is the one used in IMG/M [37], which uses the phylogeny described as part of the Genomic Encyclopedia of Bacteria and Archaea (GEBA) project [38].

Table 3. Nucleotide content and gene count levels of the assembled SBC oil seep metagenome

\begin{tabular}{|c|c|c|}
\hline Attribute & Value & $\%$ of Total \\
\hline Total base pairs sequenced (Gb) & 51.7 & $\% 100$ \\
\hline Total number of sequences (scaffolds) & 803,203 & $38.80 \%$ \\
\hline DNA, total number of bases & $495,862,225$ & $0.99 \%$ \\
\hline DNA G+C number of bases & $222,883,192$ & $44.95 \% *$ \\
\hline \multicolumn{3}{|l|}{ Genes } \\
\hline RNA genes & 7,742 & $0.68 \%$ \\
\hline rRNA genes & 1,827 & $0.16 \%$ \\
\hline $5 \mathrm{~S}$ rRNA & 420 & $0.04 \%$ \\
\hline $16 \mathrm{~S}$ rRNA & 520 & $0.05 \%$ \\
\hline $18 \mathrm{~S}$ rRNA & 12 & $0.00 \%$ \\
\hline $23 S$ rRNA & 866 & $0.08 \%$ \\
\hline $28 \mathrm{~S}$ rRNA & 9 & $0.00 \%$ \\
\hline tRNA genes & 5,915 & $0.52 \%$ \\
\hline Protein coding genes & $1,135,810$ & $99.32 \%$ \\
\hline with Product Name & 617,327 & $53.98 \%$ \\
\hline with COG & 620,853 & $54.29 \%$ \\
\hline with Pfam & 770,455 & $67.37 \%$ \\
\hline with $\mathrm{KO}$ & 461,840 & $40.39 \%$ \\
\hline with Enzyme & 265,509 & $23.22 \%$ \\
\hline with MetaCyc & 182,179 & $15.93 \%$ \\
\hline with KEGG & 266,160 & $23.27 \%$ \\
\hline COG Clusters & 4724 & $96.94 \%$ \\
\hline Pfam Clusters & 14,501 & $97.77 \%$ \\
\hline
\end{tabular}


Table 4. Percentage of genes associated with the 25 general COG functional categ ories in two assembled metagenomes from hydrocarbon-enriched environments

\begin{tabular}{crl}
\hline Code & \%age & Description \\
\hline J & 5.71 & Translation, ribosomal structure and biogenesis \\
A & 0.06 & RNA processing and modification \\
K & 5.41 & Transcription \\
L & 6.3 & Replication, recombination and repair \\
B & 0.08 & Chromatin structure and dynamics \\
D & 1.1 & Cell cycle control, cell division, chromosome partitioning \\
Y & $<0.01$ & Nuclear structure \\
V & 2.13 & Defense mechanisms \\
T & 5.54 & Signal transduction mechanisms \\
M & 6.28 & Cell wall/membrane/envelope biogenesis \\
N & 1.31 & Cell motility \\
Z & 0.02 & Cytoskeleton \\
W & $<0.01$ & Extracellular structures \\
U & 2.34 & Intracellular trafficking, secretion, and vesicular transport \\
O & 4.12 & Posttranslational modification, protein turnover, chaperones \\
C & 8.16 & Energy production and conversion \\
G & 5.16 & Carbohydrate transport and metabolism \\
E & 8.82 & Amino acid transport and metabolism \\
F & 2.66 & Nucleotide transport and metabolism \\
H & 4.2 & Coenzyme transport and metabolism \\
I & 3.6 & Lipid transport and metabolism \\
P & 5.05 & Inorganic ion transport and metabolism \\
Q & 1.88 & Secondary metabolites biosynthesis, transport and catabolism \\
R & 12.12 & General function prediction only \\
S & 7.95 & Function unknown \\
\hline & &
\end{tabular}

After removing sequences that could not be assigned phylogenetically, the assembled SBC oil seep metagenome was dominated by prokaryotic genes, with the Proteobacteria, Firmicutes, Bacteroidetes and Chloroflexi recruiting $12.9 \%, 6.5 \%, 2.3 \%$ and $2 \%$, respectively, of the $1,135,810$ protein encoding sequences with a phylogenetic classification. With 6,380 sequences, the archaeal phylum Euryarchaeota, recruited the fifth most sequences, suggesting that this phylum contributes to a large fraction of the microbial sequence data generated from the SBC seep oil. From the genes assigned to the Proteobacteria, genes assigned to Deltaproteobacteria, Epsilonproteobacteria, and Gammaproteobacteria were approximately equally frequent in the metagenome, recruiting about $15.8 \%, 15.2 \%$ and $12.4 \%$, respectively, of the 294,783 genes classified as being of bacterial origin. Within the Deltaproteobacteria, $54 \%$ of the genes categorized at the family level were assigned to strains belonging to the sulfur-reducing Desulfobacteraceae (contributing 49\%) and Desulfobulbaceae (contributing 15\%) - bacterial families frequently found associated with hydrocarbon-rich sediments [39-42]. From the genes assigned to the Epsilonproteobacteria, only $\sim 14 \%$ could be assigned at the family level within the Helicobacteraceae and Campylobacteraceae, phylogenetic groups that contain several wellcharacterized sulfur-oxidizers isolated from marine sediments and underground crude oil storage facilities [43-47], recruiting $68 \%$ and $32 \%$ of the genes, respectively. The Gammaproteobacteria was the most diverse class with the mostly anaerobic or micro-aerobic representatives from the Chromatiaceae, Ectothiorhodospiraceae, Methylococcaceae and Thiotrichaceae, recruiting $21 \%, 11 \%, 13 \%$, and $12 \%$ of the genes that could be assigned at family level. In contrast, the metagenome from the aerobic DWH oil plume was 
dominated by reads derived the Oceanospirillales $(\sim 60 \%)$, an order of the Gammaproteobacteria [14]. Within the SBC metagenome only 2\% of the genes assigned at the family level were recruited by Oceanospirillales (i.e. Bermanella marisrubri, Marinomonas mediterranea, Marinomonas posidonica and Neptuniibacter caesariensis), suggesting that the metabolic capacities of these strict aerobes might contribute only little to the functionality of the indigenous microbiome associated with the SBC seep oils. There were very few sequences attributed to Eukaryota, with representatives from the Ascomycota, Streptophyta, Cnidaria, Chlorophyta and Porifera, accounting for $<0.1 \%$ of the sequences. Plasmid population-associated genes were dominated by those associated with Firmicutes and Proteobacteria, outnumbering double-stranded DNA viruses by about two to one. The taxonomic diversity of the genes assembled from the consortium associated with SBC seep oil is summarized in Table 5. A more detailed analysis of the functional gene diversity of the SBC metagenome can be performed readily through $\underline{\mathrm{IMG} / \mathrm{M}}$.

Although gene counts of representative phyla and classes suggest phylogenetic differences, it can be assumed that the results are biased towards groups whose genomes and marker genes (e.g. $16 \mathrm{~S}$ and 18S rRNA genes) are overrepresented in genomic reference databases. While the relative abundances of between-phyla comparisons may be questionable based on differential representation in the database, the relative abundances of taxa within a phylum is reflective of the distinct metabolic conditions within an analyzed metagenome[11].

\section{Functional genes related to methane metabolism}

Natural hydrocarbon seeps represent a habitat for microbial communities that might provide the molecular tool kit for sustainable strategies to reduce the negative impact of oil spills. They also are a persistent source of methane $\left(\mathrm{CH}_{4}\right)$ [16], a greenhouse gas whose climate warming potential is 25 times greater than that of $\mathrm{CO}_{2}$ [48]. Biological $\mathrm{CH}_{4}$ oxidation in the marine ecosystem has been well documented and identified as a $\mathrm{CH}_{4}$ sink of global significance [49-51]. Anaerobic oxidation of methane (AOM), mediated by microbiomes associated with ocean sediments and deposits, has been proposed as the dominant biological process responsible for the removal of $>300 \mathrm{Tg} \mathrm{CH}_{4}$ per year from the ocean [52,53]. Despite strong research efforts aimed at understanding $\mathrm{AOM}$ and its regulation, it remains poorly understood. Until recently, AOM in marine environments was thought to be mediated by consortia of anaerobic methanotrophic archaea (ANMEs) and sulfate reducing bacteria [54,55] or alternatively by microbial consortia that couple methane oxidation to the reduction of reactive metals [56. It was not until 2010 that the first microorganism, Candidatus Methoxymirabilis oxyfera, capable of performing methane oxidation (coupled to nitrite reduction) in the absence of a metabolic partner was reported [57], followed by a second organism capable of performing single-organism AOM coupled sulfate reduction [58]. To explore if the indigenous microbial community in the SBC might have the genomic capacity to perform AOM and function as an efficient biofilter when large amounts of methane are released from the ocean subsurface, we generated a profile for genes involved in methane oxidation and methane generation. Pathway analysis based on the KEGG pathways map and the classification systems of the KEGG pathways database, was performed using the "Function Profile" tool implemented in IMG/M. Table 6 summarizes the results of the performed gene profile analysis. Key genes for AOM (and methanogenesis), including genes for the oxygen sensitive formylmethanofuran dehydrogenases (fmd; KEGG Orthology IDs K00200, K00201, K00202, K00203, K00205, K11261) and methyl coenzyme M reductases ( $\mathrm{mcr}$, KEGG Orthology IDs K00399, K00401, K00402) that catalyze the initial and terminal step of methane production, were identified within the metagenome (Table 6). The presence of the key enzymes for AOM would certainly facilitate reversed methanogenesis in an environment that is rich in non-biotic methane by members of the anaerobic methanotrophic Archaea (ANME) - as proposed previously by several groups [59,60]. ANME-mediated AOM would explain the dominance of genes from the Methanomicrobiales (containing ANME-1) and Methanosarcinaceae (containing ANME-2 and ANME-3) [61] within the archaeal genes of the SBC seep oil metagenome (totaling $\sim 56 \%$ of the archaeal genes). Active aerobic methane oxidation is restricted to a thin surface layer of seep sediments due to a limited oxygen penetration of less than $2 \mathrm{~cm}$ [62]; genes encoding methane monooxygenase (pmo; KEGG Orthology IDs K10944, K10945, K10946), a key enzyme of the aerobic methane oxidation process, were identified within the SBC seep oil metagenome (Table 6), suggesting the potential for aerobic methane oxidation. 
This finding correlates with the fact that members of the Methylococcaceae, a group of microorganisms well known for the ability to perform aerobic methane oxidation, comprised $\sim 0.31 \%$ of protein coding genes of the SBC seep oil metagenome. This is not the first time that simultaneous evidence of anaerobic and aerobic pathways for methane oxidation in SBC sediments has been reported based on metagenomic data. In 2011, Havelsrud [63] identified the complete suite of key enzymes for $\mathrm{AOM}$ in a metagenome from deep sediments (10 -
$15 \mathrm{~cm}$ ) offshore Coal Oil Point in the SBC, whereas sequencing of the shallower sediments $(0-4 \mathrm{~cm})$ failed to detect two of the key enzymes (methenyltetrahydromethanopterin cyclohydrolase and methylenetetrahydromethanopterin dehydrogenase) of AOM. Genes annotated as methane monooxygenase were identified within the shallow sediment metagenome [63], suggesting the possibility that the upper sediment layers of SBC sediments contain pockets of aerobic and anaerobic microhabitats.

Table 5. Overview of taxonomic gene diversity in the assembled SBC oil seep metagenome.

\begin{tabular}{|c|c|c|}
\hline Domain & Phylum & $\%$ Hits \\
\hline \multicolumn{3}{|l|}{ Archaea } \\
\hline & Euryarchaeota & 0.56 \\
\hline & Crenarchaeota & 0.01 \\
\hline & Thaumarchaeota & 0.01 \\
\hline \multicolumn{3}{|l|}{ Bacteria } \\
\hline & Proteobacteria & 12.88 \\
\hline & Firmicutes & 6.48 \\
\hline & Bacteroidetes & 2.33 \\
\hline & Chloroflexi & 2.01 \\
\hline & Actinobacteria & 0.48 \\
\hline & Cyanobacteria & 0.34 \\
\hline & Ignavibacteria & 0.30 \\
\hline & unclassified & 0.20 \\
\hline & Acidobacteria & 0.13 \\
\hline & Verrucomicrobia & 0.12 \\
\hline & Planctomycetes & 0.10 \\
\hline & Deinococcus-Thermus & 0.10 \\
\hline & Chlorobi & 0.09 \\
\hline & Spirochaetes & 0.08 \\
\hline & Synergistetes & 0.04 \\
\hline & Thermotogae & 0.04 \\
\hline & Deferribacteres & 0.04 \\
\hline & Aquificae & 0.04 \\
\hline & Nitrospirae & 0.03 \\
\hline & Fusobacteria & 0.03 \\
\hline & Thermodesulfobacteria & 0.02 \\
\hline & Poribacteria & 0.02 \\
\hline & Lentisphaerae & 0.01 \\
\hline & Dictyoglomi & 0.01 \\
\hline & Gemmatimonadetes & 0.01 \\
\hline & Tenericutes & 0.01 \\
\hline & Chlamydiae & 0.01 \\
\hline \multicolumn{3}{|l|}{ Eukarya } \\
\hline & Ascomycota & 0.01 \\
\hline & Streptophyta & 0.01 \\
\hline & Cnidaria & 0.01 \\
\hline & Chlorophyta & 0.01 \\
\hline & Porifera & 00.1 \\
\hline & unclassified & 0.01 \\
\hline Unassigned & & 73.38 \\
\hline
\end{tabular}


Table 6. Counts of genes associated with methane metabolism in SBC seep oil metagenome

KEGG Orthology ID

K00192

K00195

K00440

K00441

K00443

K05884

K05979

K06034

K08097

K13039

K11212

K11780

K11781

K12234

K14941

K00018

K00024

K00600

K00830

K00850

K00863

K01595

K01624

K01689

K03841

K08093

K08094

K08691

K08692

K11529

K13812

K13831

K14067

K16370

K16158

K10944

K10945

K10946

K00200

K00201

K00202
Description

Gene count

Acetyl-CoA pathway

21

Acetyl-CoA pathway

6

Coenzyme F420 hydrog enase

Coenzyme F420 hydrogenase

62

Coenzyme F420 hydrog enase

Coenzyme M biosynthesis 11

Coenzyme M biosynthesis

20

Coenzyme $\mathrm{M}$ biosynthesis

Coenzyme M biosynthesis

13

Coenzyme M biosynthesis

F420 biosynthesis

63

F420 biosynthesis

7

F420 biosynthesis

F420 biosynthesis

66

F420 biosynthesis

40

Formaldehyde assimilation

Formaldehyde assimilation

277

Formaldehyde assimilation

463

Formaldehyde assimilation

116

Formaldehyde assimilation

558

Formaldehyde assimilation 2

Formaldehyde assimilation 133

Formaldehyde assimilation $\quad 276$

Formaldehyde assimilation 380

Formaldehyde assimilation $\quad 122$

Formaldehyde assimilation 20

Formaldehyde assimilation $\quad 32$

Formaldehyde assimilation $\quad 35$

Formaldehyde assimilation $\quad 13$

Formaldehyde assimilation $\quad 6$

Formaldehyde assimilation $\quad 14$

Formaldehyde assimilation 26

Formaldehyde assimilation $\quad 14$

Formaldehyde assimilation $\quad 10$

Methane oxidation 2

Methane oxidation; Nitrification 3

Methane oxidation; Nitrification 3

Methane oxidation; Nitrification 19

Methanogenesis 20

Methanogenesis 27

Methanogenesis 
Table 6 (cont.). Counts of genes associated with methane metabolism in SBC seep oil metagenome

KEGG Orthology ID

K00203

K00204

K00205

K00319

K00320

K00399

K00401

K00402

K00577

K00578

K00579

K00580

K00581

K00582

K00583

K00584

K00625

K00672

K00925

K01499

K01895

K03388

K03389

K03390

K04480

K11260

K11261

K13788

K14080

K14081

K14082

K14083

K14084

K16176

K16177

K16178

K16179

K00193

K00194

K00197
Description

Gene count

Methanog enesis

Methanogenesis

Methanogenesis

Methanog enesis

Methanog enesis

Methanog enesis

Methanogenesis

Methanog enesis

Methanog enesis

Methanogenesis

Methanog enesis

Methanogenesis

Methanog enesis

Methanog enesis

Methanog enesis

Methanog enesis

Methanog enesis

Methanog enesis

Methanog enesis

Methanog enesis

Methanogenesis

Methanog enesis

Methanogenesis

Methanog enesis

Methanogenesis

Methanogenesis

Methanog enesis

Methanog enesis

Methanogenesis

Methanogenesis

Methanog enesis

Methanogenesis

Methanog enesis

Methanogenesis

Methanogenesis

Methanogenesis

Methanog enesis

Methanogenesis; Acetyl-CoA pathway

Methanog enesis; Acetyl-CoA pathway

Methanogenesis; Acetyl-CoA pathway

8

0

10

5

111

10

7

1620

234

137

1

6

67

88

3

1

10

638

56

50

3

9

9

16

84

149 
To investigate the presence of genomic material from sulfur-reducing bacteria (SRB) - microbes mediating reverse methanogenesis - we analyzed the metagenomes for genes encoding dissimilatory sulfite reductase ( $d s r$; KEGG Orthology IDs K11180, K11181). We identified a total of 204 reads annotated as $d s r$ within the SBC seep oil metagenome (data not shown), suggesting that AOM via reverse methanogenesis - a process mediated primarily by consortia of archaeal methane oxidizers and bacterial sulfur reducers - may occur during the microbially mediated biofiltration of $\mathrm{CH}_{4}$ in the hydrocarbon rich sediments. The proposed $\mathrm{CH}_{4}$ biofiltration process under anaerobic conditions within the SBC sediments is summarized in Figure 1. Analysis of the metagenome data from the SBC revealed a total of 2,373 genes covering the complete suite of enzymes necessary for anaerobic methane oxidation/methanogenesis outlined in Figure 1. In contrast, the DWH oil plume metagenome (accessible through $\underline{\mathrm{IMG} / \mathrm{M}}$ ) contained only a total of 9 genes (i.e. fwd, $h d r$ and $m e r$ ) that were assigned to this pathways that has been reported as a characteristic feature for microbiomes associated with anaerobic habitats rich in hydrocarbons $[42,64,65]$.

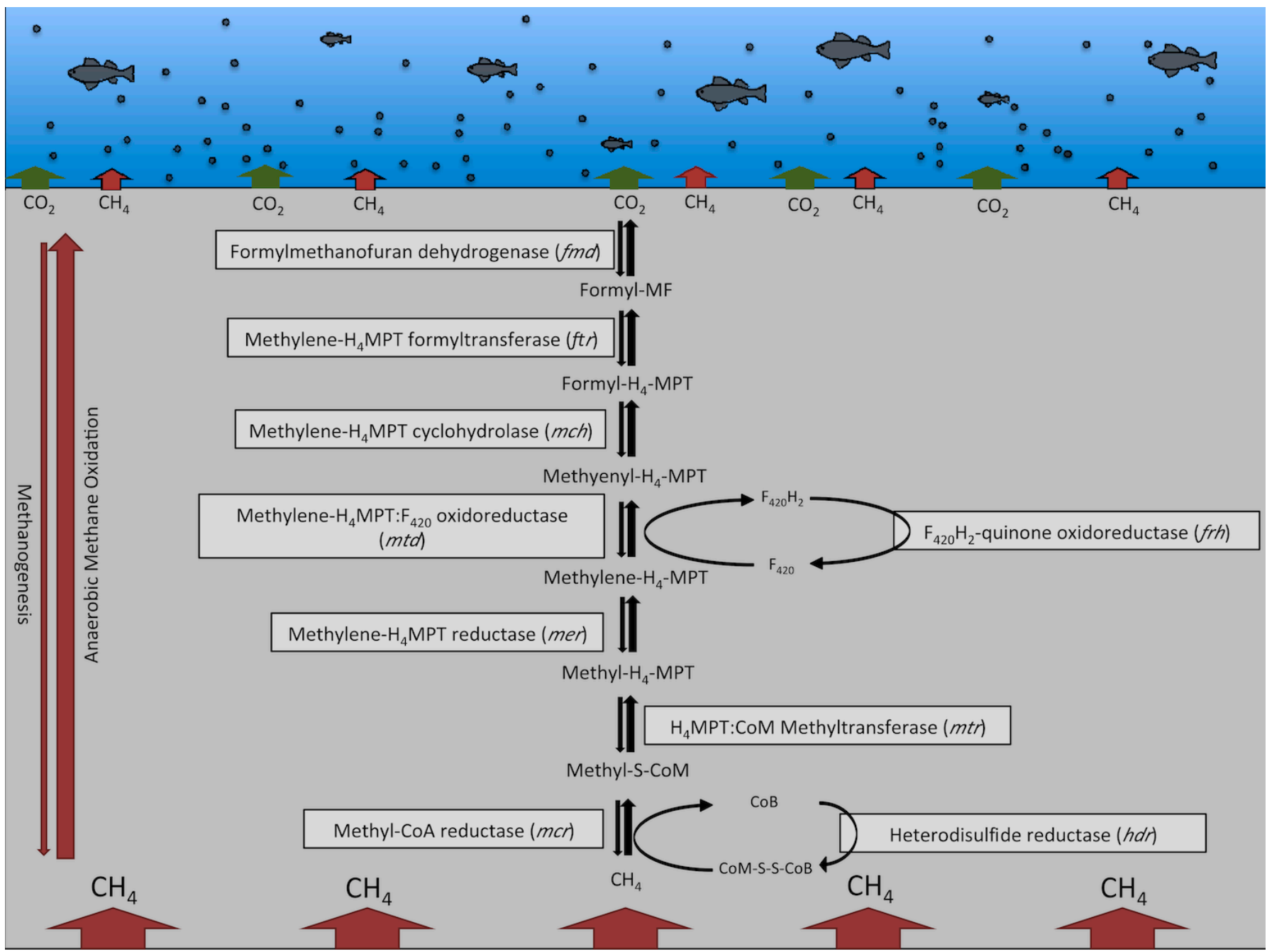

Figure 1. Anaerobic methane oxidation/methanogenesis in sediments of the Santa Barbara Channel. Proposed pathway based on the genes involved in AOM and methanogenesis identified in the metagenome from Santa Barbara Channel seep oil. 


\section{Conclusion}

Sequencing of eDNA extracted from crude oil that was collected from an active hydrocarbon seep in the Santa Barbara Channel (SBC) and subsequent taxonomic profiling of the protein coding genes suggests that the microbial processes associated with this particular microbiome are dominated by members of the Proteobacteria, Firmicutes, Bacteroidetes, Chloroflexi and Euryarchaeota. Members of the Oceanospirillales, a bacterial order that recruited more than $60 \%$ of the genes from the DWH oil plume metagenome [14], recruited only a small fraction $(<2 \%)$ of the genes from the SBC metagenome, which suggests that Oceanospirillales might play a less significant role in the microbially mediated hydrocarbon conversion within the SBC seep oil compared to the DWH plume oil, which had an average oxygen saturation of 59\% [4]. Oxygen depletion in SBC sediment has been reported previously [62] and we hypothesize that the distinct taxonomic fingerprint of the genes assembled from the SBC seep oil and DWH oil plume metagenome data is caused in part by the different concentrations of oxygen within these oils. This hypothesis is supported by recent findings by Kimes et al [66] that showed that Oceanospirillales contributed only a small fraction to the overall microbiome associated with cores collected from low oxygen sediments in the GoM. The hypothesis that the SBC seep oil contains low concentrations of oxygen and thus facilitates anaerobic processes is supported by the

\section{Acknowledgements}

MHess, ERH, HP and the work performed in the laboratory of MHess were funded by Washington State University. The work conducted by the U.S. Department of Energy Joint Genome Institute was supported by the Office of Science of the U.S. Department of Energy under Contract No. DE-AC02-05CH11231. Work conducted by NMS and JAG was supported by the U.S. Deptartment of Energy under Contract DE-AC0206CH11357. We are extremely thankful to our colleagues who provided letters of support for our CSP proposal. Additional thanks go to staff members of the Chemical and Biological Process Development Group - results from our functional gene analysis of the SBC seep oil metagenome, which revealed the presence of the genes essential for anaerobic methane oxidation, and the findings that members of the anaerobic methanotrophic archaea comprise the majority of the archaeal genes within the SBC seep oil metagenome. Taking these findings into consideration, it appears plausible that the taxonomic and functional make-up of the metagenome associated with the SBC seep oil and the DWH plume oil depends rather on the oxygen saturation of the oil then its geographical origin and that the metabolic capability of the associated microbiome might be dynamic. However, further studies are necessary to obtain a better understanding of the biological processes that are associated with these hydrocarbons and their microbially mediated degradation process.

The metagenome from natural oil that seeps into the SBC and the metagenome associated with the oil plume that formed in the aftermath of the DWH blowout are publicly accessible for further analysis at $\underline{\mathrm{IMG} / \mathrm{M}}$. This provides an unique opportunity to study the metabolic profile of a hydrocarbon degrading community from the SBC and to infer the metabolic differences between microbial communities associated with natural hydrocarbons that enter the marine ecosystem at different geographical locations.

in particular David Culley, Jon Magnuson, Kenneth Bruno, Jim Collett, and Scott Baker - and the Microbial Community Initiative - in particular Allan Konopka, Jim Fredrickson and Steve Lindeman - at PNNL for scientific discussions throughout the project. Conception and design of the experiments: MHess, TDL, JAG, JJ; Performance of the experim ents: MHess, ERH, TDL; Generation and processing of data: MHess, ERH, HP, SM, TGR, ST, BF, AC, IP, MHuntemann; Analysis of the data: MHess, ERH, SM, AC, AP; D rafting of this article: MHess, NMS, TDL, JAG, ST, JJ

2. Lindstrom JE, Prince RC, Clark JC, Grossman MJ, Yeager TR, Braddock JF, Brown EJ. Microbial populations and hydrocarbon biodegradation potentials in fertilized shoreline sediments affected by the T/V Exxon Valdez oil spill. App/ Environ Microbiol 1991; 57:2514-2522. PubMed 
3. Bragg JR, Prince RC, Harner EJ, Atlas RM. Effectiveness of bioremediation for the Exxon Valdez oil spill. Nature 1994; 368:413-418. http://dx.doi.org/10.1038/368413a0

4. Hazen TC, Dubinsky EA, DeSantis TZ, Andersen GL, Piceno YM, Sing N N, Jansson JK, Probst A, Borglin SE, Fortney JL, et al. Deep-sea oil plume enriches indigenous oil-deg rading bacteria. Science 2010; 330:204-208. PubMed http://dx.doi.org/10.1126/science.1195979

5. Mascarelli A. The mystery of the missing oil plume. Nature 2010; 467:16. PubMed http://dx.doi.org/10.1038/467016a

6. Head IM, Jones DM, Roling WF. Marine microorganisms make a meal of oil. Nat Rev Microbiol 2006; 4:173-182. $\underline{\text { PubMed }}$ http://dx.doi.org/10.1038/nrmicro1348

7. Redmond MC, Valentine DL. Natural gas and temperature structured a microbial community response to the Deepwater Horizon oil spill. Proc Natl Acad Sci USA 2011; 109:20292-20297. $\underline{\text { PubMed }}$ http://dx.doi.org/10.1073/pnas. 1108756108

8. Alonso-Gutiérrez J, Figueras A, Albaiges J, Jimenez N, Vinas M, Solanas AM, Novoa B. Bacterial communities from shoreline environments (costa da morte, northwestern Spain) affected by the prestige oil spill. App/ Environ Microbiol 2009; 75:3407-3418. $\underline{\text { PubMed }}$ http://dx.doi.org/10.1128/AEM.01776-08

9. Rinke C, Schwientek P, Sczyrba A, Ivanova NN, Anderson IJ, Cheng JF, Darling A, Malfatti S, Swan BK, Gies EA, et al. Insights into the phylogeny and coding potential of microbial dark matter. Nature 2013; 499:431-437. PubMed http://dx.doi.org/10.1038/nature12352

10. Hess M, Sczyrba A, Egan R, Kim TW, Chokhawala H, Schroth G, Luo S, Clark DS, Chen $\mathrm{F}$, Zhang $\mathrm{T}$, et al. Metagenomic discovery of biomass-deg rading genes and genomes from cow rumen. Science 2011; 331:463-467. PubMed http://dx.doi.org/10.1126/science.1200387

11. Kimes NE, Callaghan AV, Aktas DF, Smith WL, Sunner J, Golding B, Drozdowska M, Hazen TC, Suflita JM, Morris PJ. Metag enomic analysis and metabolite profiling of deep-sea sediments from the Gulf of Mexico following the Deepwater Horizon oil spill. Frontiers in Mic robiology 2013; 4:50. PubMed http://dx.doi.org/10.3389/fmicb.2013.00050

12. Liu Z, Liu J. Evaluating bacterial community structures in oil collected from the sea surface and sediment in the northern Gulf of Mexico after the Deepwater Horizon oil spill. MicrobiologyOpen 2013; 2:492-504. PubMed http://dx.doi.org/10.1002/mbo3.89

13. Beazley MJ, Martinez RJ, Rajan S, Powell J, Piceno YM, Tom LM, Andersen GL, Hazen TC, Van Nostrand JD, Zhou J, et al. Microbial community analysis of a coastal salt marsh affected by the Deepwater Horizon oil spill. PLoS ONE 2012; 7:e41305. PubMed http://dx.doi.org/10.1371/journal.pone.0041305

14. Mason OU, Hazen TC, Borglin S, Chain PS, Dubinsky EA, Fortney JL, Han J, Holman HY, Hultman J, Lamendella R, et al. Metagenome, metatranscriptome and single-cell sequencing reveal microbial response to Deepwater Horizon oil spill. ISME J 2012; 6:1715-1727. $\underline{\text { PubMed }}$ http://dx.doi.org/10.1038/ismej.2012.59

15. Lu Z, Deng Y, Van Nostrand JD, He Z, Voordeckers J, Zhou A, Lee YJ, Mason OU, Dubinsky EA, Chavarria KL, et al. Microbial gene functions enriched in the Deepwater Horizon deep-sea oil plume. ISME J 2012; 6:451-460. PubMed http://dx.doi.org/10.1038/ismej.2011.91

16. Hornafius JS, Quigley D, Luyendyk BP. The world's most spectacular marine hydrocarbon seeps (Coal Oil Point, Santa Barbara Channel, California): Quantification of emissions. Journal of Geophysical Research: Oceans 1999;

104(C9):20703-20711. http://dx.doi.org/10.1029/1999/C900148

17. Field D, Garrity G, Gray T, Morrison N, Seleng ut J, Sterk P, Tatusova T, Thomson N, Allen MJ, Angiuoli SV, et al. The minimum information about a genome sequence (MIGS) specification. Nat Biotechnol 2008; 26:541-547. PubMed http://dx.doi.org/10.1038/nbt1360

18. Ashburner M, Ball CA, Blake JA, Botstein D, Butler H, Cherry JM, Davis AP, Dolinski K, Dwight SS, Eppig JT, et al. Gene Ontology: tool for the unification of biology. Nat Genet 2000; 25:2 5-29. PubMed http://dx.doi.org/10.1038/75556

19. Lorenson T, Leifer I, Wong F, Rosenbauer R, Campbell P, Hostetter L, Angela, Frances H, Greinert J, Finlayson D, Bradley E and others. Biomarker Chemistry and Flux Quantification Methods for Natural Petroleum Seeps and Produced Oils, Offshore Southern California. Geological Survey Scientific Investigations Report 2011:1-56.

20. Hawley ER, Lorenson TD, Hess M. Analysis of microbial communities associated with natural 
oils that seep into the Santa Barbara Channel: Linking community dynamics with biological hydrocarbon degradation. 8th Annual DOE Joint Genome Institue User Meeting 2013.

21. Luo R, Liu B, Xie Y, Li Z, Huang W, Yuan J, He G, Chen Y, Pan Q, Liu Y, et al. SOAPdenovo2: an empirically improved memory-efficient short-read de novo assembler. GigaScience 2012; 1:18. PubMed http://dx.doi.org/10.1186/2047-217X-1$\underline{18}$

22. AMOS. http://sourceforg e.net/projects/amos

23. Aligner BW. (BWA). http://biobwa.sourceforge.net/

24. Fast Length Adjustment of SHort reads (FLASH). http://sourceforg e.net/projects/flashpage

25. Morg ulis A, Gertz EM, Schaffer AA, Agarwala R. A fast and symmetric DUST implementation to mask low-complexity DNA sequences. Journal of Computational Biology: a journal of computational molecular cell biology 2006;13(5):102840.

26. Edgar RC. Search and clustering orders of magnitude faster than BLAST. Bioinformatics 2010;

26:2460-2 461. PubMed http://dx.doi.org/10.1093/bioinformatics/btq461

27. Lowe TM, Eddy SR. tRNAscan-SE: A prog ram for improved detection of transfer RNA genes in genomic sequence. Nucleic Acids Res 1997;

25:955-964. PubMed http://dx.doi.org/10.1093/nar/25.5.0955

28. Altschul SF, Madden TL, Schaffer AA, Zhang JH, Zhang Z, Miller W, Lipman DJ. Gapped BLAST and PSI-BLAST: a new generation of protein database search prog rams. Nucleic Acids Res 1997; 25:3389-3402. PubMed http://dx.doi.org/10.1093/nar/25.17.3389

29. Eddy SR. Accelerated Profile HMM Searches. PLOS Comput Biol 2011; 7: e1002195. PubMed http://dx.doi.org/10.1371/journal.pcbi.1002195

30. Besemer J, Borodovsky M. GeneMark: web software for gene finding in prokaryotes, eukaryotes and viruses. Nucleic Acids Res 2005; 33:W451W454. PubMed http://dx.doi.org/10.1093/nar/gki487

31. Noguchi H, Park J, Takagi T. MetaGene: prokaryotic gene finding from environmental genome shotg un sequences. Nucleic Acids Res 2006; 34:5623-5630. PubMed http://dx.doi.org/10.1093/nar/gkl723
32. Hyatt $\mathrm{D}$, Chen GL, LoCascio PF, Land ML, Larimer FW, Hauser LJ. Prodig al: prokaryotic gene recognition and translation initiation site identification. BMC Bioinformatics 2010; 11:119. PubMed http://dx.doi.org/10.1186/1471-2105-11-119

33. Rho MN, Tang HX, Ye YZ. Frag GeneScan: predicting genes in short and error-prone reads. $\mathrm{Nu}$ cleic Acids Res 2010; 38:e191. PubMed http://dx.doi.org/10.1093/nar/gkq747

34. Tatusov RL, Fedorova ND, Jackson JD, Jacobs AR, Kiryutin B, Koonin EV, Krylov DM, Mazumder R, Mekhedov SL, Nikolskaya AN, et al. The COG database: an updated version includes eukaryotes. BMC Bioinformatics 2003; 4:41. PubMed http://dx.doi.org/10.1186/1471-2105-4-41

35. Punta M, Coggill PC, Eberhardt RY, Mistry J, Tate J, Boursnell C, Pang N, Forslund K, Ceric G, Clements J, et al. The Pfam protein families database. Nucleic Acids Res 2012; 40(D1):D290D301. PubMed http://dx.doi.org/10.1093/nar/gkr1065

36. Mao XZ, Cai T, Olyarchuk JG, Wei LP. Automated genome annotation and pathway identification using the KEGG Orthology (KO) as a controlled vocabulary. Bioinformatics 2005; 21:3787-3793. PubMed http://dx.doi.org/10.1093/bioinformatics/bti430

37. Markowitz VM, Chen IM, Chu K, Szeto E, Palaniappan K, Grechkin Y, Ratner A, Jacob B, Pati $A$, Huntemann $M$, et al. IMG/M: the integ rated metagenome data management and comparative analysis system. Nucleic Acids Res 2012; 40:D123-D129. PubMed http://dx.doi.org/10.1093/nar/gkr975

38. Wu D, Hugenholtz P, Mavromatis K, Pukall R, Dalin E, Ivanova NN, Kunin V, Goodwin L, Wu $M$, Tindall BJ, et al. A phylogeny-driven Genomic Encyclopaedia of Bacteria and Archaea. Nature 2009; 462:1056-1060. PubMed http://dx.doi.org/10.1038/nature08656

39. Acosta-González A, Rosselló-Móra R, Marqués S. Characterization of the anaerobic microbial community in oil-polluted subtidal sediments: aromatic biodeg radation potential after the Prestige oil spill. Environ Microbiol 2013; 15:77-92. PubMed http://dx.doi.org/10.1111/j.1462$\underline{2920.2012 .02782 . x}$

40. Cravo-Laureau C, Labat C, Joulian C, Matheron R, Hirschler-Réa A. Desulfatiferula olefinivorans gen. nov., sp. nov., a long-chain n-alkene-deg rading, sulfate-reducing bacterium. Int / Syst Evol 
Microbiol 2007; 57:2699-2 702. PubMed

http://dx.doi.org/10.1099/ijs.0.65240-0

41. Winderl C, Anneser B, Griebler C, Meckenstock $R U$, Lueders T. Depth-resolved quantification of anaerobic toluene deg raders and aquifer microbial community patterns in distinct redox zones of a tar oil contaminant plume. App/ Environ

Microbiol 2008; 74:792-801. PubMed

http://dx.doi.org/10.1128/AEM.01951-07

42. Lloyd KG, Albert DB, Biddle JF, Chanton JP, Pizarro O, Teske A. Spatial structure and activity of sedimentary microbial communities underlying a Beggiatoa spp. mat in a Gulf of Mexico hydrocarbon seep. PLoS ONE 2010; 5:e8738. PubMed http://dx.doi.org/10.1371/journal.pone.0008738

43. Sievert SM, Scott KM, Klotz MG, Chain PS, Hauser LJ, Hemp J, Hügler M, Land M, Lapidus A, Larimer FW, et al. Genome of the epsilonproteobacterial chemolithoautotroph Sulfurimonas denitrificans. Appl Environ Microbiol 2008; 74:1145-1156. PubMed http://dx.doi.org/10.1128/AEM.01844-07

44. Sikorski J, Munk C, Lapidus A, Ngatchou Djao OD, Lucas S, Glavina Del Rio T, Nolan M, Tice $\mathrm{H}$, Han C, Cheng JF, et al. Complete genome sequence of Sulfurimonas autotrophica type strain (OK10). Stand Genomic Sci 2010 ; 3:194-202. PubMed

45. Kodama Y, Watanabe K. Sulfuricurvum kujiense gen. nov., sp. nov., a facultatively anaerobic, chemolithoautotrophic, sulfur-oxidizing bacterium isolated from an underg round crude-oil storage cavity. Int I Syst Evol Microbiol 2004;

54:2297-2300. PubMed http://dx.doi.org/10.1099/ijs.0.63243-0

46. Wirsen CO, Sievert SM, Cavanaugh CM, Molyneaux SJ, Ahmad A, Taylor LT, DeLong EF, Taylor CD. Characterization of an autotrophic sulfide-oxidizing marine Arcobacter sp. that produces filamentous sulfur. Appl Environ Microbiol 2002; 68:316-32 5. PubMed

http://dx.doi.org/10.1128/AEM.68.1.316$\underline{325.2002}$

47. Kodama Y. Ha le T, Watanabe K. Sulfurospirillum cavolei sp. nov., a facultatively anaerobic sulfurreducing bacterium isolated from an underg round crude oil storage cavity. Int I Syst Evol Microbiol 2007; 57:82 7-831. PubMed http://dx.doi.org/10.1099/ijs.0.64823-0

48. IPCC. Climate Change 2007 - The Physical Science Basis. 2007. Contribution of Working Group I to the Fourth Assessment Report of the Intergov- ernmental Panel on Climate Change Cambridge University Press, Cambridge, United King dom and New York, NY, USA, 996 pp.

49. Kessler JD, Valentine DL, Redmond MC, Du M, Chan EW, Mendes SD, Quiroz EW, Villanueva CJ, Shusta SS, Werra LM, et al. A persistent oxygen anomaly reveals the fate of spilled methane in the deep. Gulf Mex Sci 2011; 331:312-315. PubMed

50. Reeburgh WS. Oceanic methane biog eochemistry. Chem Rev 2007; 107:486-513. PubMed http://dx.doi.org/10.1021/cr050362v

51. Siegert M, Kruger M, Teichert B, Wiedicke M, Schippers A. Anaerobic Oxidation of Methane at a Marine Methane Seep in a Forearc Sediment Basin off Sumatra, Indian Ocean. Frontiers in $\mathrm{Mi}$ crobiology 2011; 2:249. PubMed http://dx.doi.org/10.3389/fmicb.2011.00249

52. Wankel SD, Adams MM, Johnston DT, Hansel CM, Joye SB, Girg uis PR. Anaerobic methane oxidation in metalliferous hydrothermal sediments: influence on carbon flux and decoupling from sulfate reduction. Environ Microbiol 2012;

14:2726-2740. PubMed

http://dx.doi.org/10.1111/j.14622920.2012.02825.x

53. Callag han AV. Enzymes involved in the anaerobic oxidation of n-alkanes: from methane to longchain paraffins. Frontiers in Microbiology 2013; 4:89. PubMed http://dx.doi.org/10.3389/fmicb.2013.00089

54. Hinrichs KU, Hayes JM, Sylva SP, Brewer PG, DeLong EF. Methane-consuming archaebacteria in marine sediments. Nature 1999; 398:802-805. PubMed http://dx.doi.org/10.1038/19751

55. Boetius A, Ravenschlag K, Schubert CJ, Rickert D, Widdel F, Gieseke A, Amann R, Jorg ensen BB, Witte $U$, Pfannkuche O. A marine microbial consortium apparently mediating anaerobic oxidation of methane. Nature 2000; 407:623-626. PubMed http://dx.doi.org/10.1038/35036572

56. Beal EJ, House $\mathrm{CH}$, Orphan VJ. Mang anese- and iron-dependent marine methane oxidation. Science 2009; 325:184-187. PubMed http://dx.doi.org/10.1126/science.1169984

57. Ettwig KF, Butler MK, Le Paslier D, Pelletier E, Mangenot S, Kuypers MM, Schreiber F, Dutilh BE, Zedelius J, de Beer D, et al. Nitrite-driven anaerobic methane oxidation by oxygenic bacteria. $\mathrm{Na}$ ture 2010; 464:543-548. PubMed http://dx.doi.org/10.1038/nature08883 
58. Milucka J, Ferdelman TG, Polerecky L, Franzke D, Wegener G, Schmid M, Lieberwirth I, Wagner M, Widdel F, Kuypers MMM. Zero-valent sulphur is a key intermediate in marine methane oxidation. Nature 2012; 491:541-546. PubMed http://dx.doi.org/10.1038/nature11656

59. Stokke R, Roalkvam I, Lanzen A, Haflidason H, Steen $\mathrm{IH}$. Integ rated metag enomic and metaproteomic analyses of an ANME-1dominated community in marine cold seep sediments. Environ Microbio/ 2012; 14:1333-1346. PubMed http://dx.doi.org/10.1111/j.14622920.2012.02716.x

60. Hallam SJ, Putnam N, Preston CM, Detter JC, Rokhsar D, Richardson PM, DeLong EF. Reverse methanogenesis: testing the hypothesis with environmental genomics. Science 2004; 305:14571462. PubMed http://dx.doi.org/10.1126/science.1100025

61. Thauer RK. Anaerobic oxidation of methane with sulfate: on the reversibility of the reactions that are catalyzed by enzymes also involved in methanog enesis from CO2. Curr Opin Microbiol 2011; 14:292-299. PubMed http://dx.doi.org/10.1016/j.mib.2011.03.003

62. Treude T, Ziebis W. Methane oxidation in permeable sediments at hydrocarbon seeps in the Santa Barbara Channel, California. Biogeosciences 2010; 7:3095-3108. http://dx.doi.org/10.5194/bg$\underline{\text { 7-3095-2010 }}$
63. Håvelsrud $\mathrm{OE}$, Haverkamp $\mathrm{TH}$, Kristensen $\mathrm{T}$, Jakobsen KS, Rike AG. A metag enomic study of methanotrophic microorg anisms in Coal Oil Point seep sediments. BMC Microbiol 2011; 11:221. PubMed http://dx.doi.org/10.1186/1471-2180-11$\underline{221}$

64. Rubin-Blum M, Antler G, Turchyn AV, Tsadok R, Goodman-Tchernov BN, Shemesh E, Austin JA, Jr., Coleman DF, Makovsky Y, Sivan O, Tchernov D. Hydrocarbon-related microbial processes in the deep sediments of the Eastern Mediterranean Levantine Basin. [Epub ahead of print]. FEMS Microbiol Ecol 2013. PubMed http://dx.doi.org/10.1111/1574-6941.12264

65. Håvelsrud $\mathrm{OE}$, Haverkamp $\mathrm{TH}$, Kristensen $\mathrm{T}$, Jakobsen KS, Rike AG. A metagenomic study of methanotrophic microorganisms in Coal Oil Point seep sediments. BMC Microbiol. 2011; 11:221. PubMed http://dx.doi.org/10.1186/1471-2180-11$\underline{221}$

66. Kimes NE, Callaghan AV, Aktas DF, Smith WL, Sunner J, Golding B, Drozdowska M, Hazen TC, Suflita JM, Morris PJ. Metag enomic analysis and metabolite profiling of deep-sea sediments from the Gulf of Mexico following the Deepwater Horizon oil spill. Front Microbiol. 2013; 4:50. PubMed http://dx.doi.org/10.3389/fmicb.2013.00050 